\section{QPB}

1. Setor de Função Pulmonar e Fisiologia Clínica do Exercício SEFICE - Disciplina de Pneumologia, Departamento de Medicina, Escola Paulista de Medicina, Universidade Federal de São Paulo - UNIFESP São Paulo (SP) Brasil.

2. Instituto Dante Pazzanese de Cardiologia, São Paulo (SP) Brasil.

3. Departamento de Fisioterapia, Universidade Federal de São Carlos UFSCAR - São Carlos (SP) Brasil.

4. Respiratory Investigation Unit, Division of Respiratory and Critical Care Medicine, Department of Medicine Queen's University, Kingston (ON) Canada.

5. Laboratory of Clinical Exercise Physiology, Division of Respiratory and Critical Care Medicine, Department of Medicine, Queen's University, Kingston (ON) Canada.

Submitted: 9 November 2015.

Accepted: 9 May 2016.

Study carried out in the Setor de Função Pulmonar e Fisiologia Clínica do Exercício - SEFICE - Disciplina de Pneumologia,

Departamento de Medicina, Escola

Paulista de Medicina, Universidade

Federal de São Paulo - UNIFESP -

São Paulo, Brazil.

\title{
Influence of heart failure on resting lung volumes in patients with COPD
}

\author{
Aline Soares de Souza ${ }^{1,2}$, Priscila Abreu Sperandio',2, Adriana Mazzuco, ${ }^{1,3}$, \\ Maria Clara Alencar ${ }^{1}$, Flávio Ferlin Arbex ${ }^{1}$, Mayron Faria de Oliveira ${ }^{1,2}$, \\ Denis Eunan O’Donnell ${ }^{4}$, José Alberto Neder ${ }^{1,5}$
}

\begin{abstract}
Objective: To evaluate the influence of chronic heart failure (CHF) on resting lung volumes in patients with COPD, i.e., inspiratory fraction - inspiratory capacity (IC)/TLC and relative inspiratory reserve-[1 - (end-inspiratory lung volume/TLC)]. Methods: This was a prospective study involving 56 patients with COPD-24 (23 males/1 female) with COPD +CHF and 32 (28 males/4 females) with COPD only-who, after careful clinical stabilization, underwent spirometry (with forced and slow maneuvers) and whole-body plethysmography. Results: Although $\mathrm{FEV}_{1}$, as well as the $\mathrm{FEV}_{1} / \mathrm{FVC}$ and $\mathrm{FEV}_{1} / \mathrm{slow}$ vital capacity ratios, were higher in the COPD+CHF group than in the COPD group, all major "static" volumes-RV, functional residual capacity (FRC), and TLC-were lower in the former group $(p<0.05)$. There was a greater reduction in $F R C$ than in $R V$, resulting in the expiratory reserve volume being lower in the COPD+CHF group than in the COPD group. There were relatively proportional reductions in FRC and TLC in the two groups; therefore, IC was also comparable. Consequently, the inspiratory fraction was higher in the COPD+CHF group than in the COPD group ( $0.42 \pm 0.10$ vs. $0.36 \pm 0.10 ; p<0.05)$. Although the tidal volume/IC ratio was higher in the COPD+CHF group, the relative inspiratory reserve was remarkably similar between the two groups $(0.35 \pm 0.09$ vs. $0.44 \pm 0.14 ; p<0.05)$. Conclusions: Despite the restrictive effects of $\mathrm{CHF}$, patients with $\mathrm{COPD}+\mathrm{CHF}$ have relatively higher inspiratory limits (a greater inspiratory fraction). However, those patients use only a part of those limits, probably in order to avoid critical reductions in inspiratory reserve and increases in elastic recoil.
\end{abstract}

Keywords: Respiratory function tests; Pulmonary disease, chronic obstructive; Heart failure; Spirometry.

\section{INTRODUCTION}

The pathophysiological mechanisms of COPD are largely expiratory and obstructive. However, their consequences are inspiratory and elastic. ${ }^{(1)}$ In other words, expiratory flow limitation and the resulting air trapping/lung hyperinflation tend to increase operating lung volumes, thus reducing inspiratory reserve volume (IRV). (2) Pulmonary function tests show lower inspiratory fraction-inspiratory capacity (IC)/TLC ${ }^{(3,4)}$-and relative inspiratory reserve- $[1$ - (end-inspiratory lung volume $(\text { EILV)/TLC) }]^{(5)}$-in patients with the aforementioned abnormalities than in normal individuals. Given that the consequent reduction in dynamic compliance increases operating lung volumes-thus worsening neuromechanical dissociation and dyspnea ${ }^{(6)}$-it is clinically important to measure inspiratory fraction and relative inspiratory reserve in patients with COPD.

In this context, COPD is associated with several comorbidities that can affect lung volumes and their complex interrelationships. Because of its high prevalence and impact on morbidity and mortality, chronic heart failure
(CHF) with reduced ejection fraction is chief among them. (7-9) Several studies have shown that chronic pulmonary congestion, septal thickening, inspiratory muscle weakness, and the compressive effects of cardiomegaly often reduce IC in patients with CHF. ${ }^{(10-12)}$ However, because TLC and tidal volume $\left(\mathrm{V}_{\mathrm{T}}\right)$ changes are variable, ${ }^{(13-16)}$ the way in which inspiratory fraction and relative inspiratory reserve are affected can vary across patients. Therefore, if the aforementioned consequences of CHF are also observed in patients with COPD+CHF and if end-expiratory lung volume (EELV) and EILV remain stable, ${ }^{(17)}$ inspiratory fraction and relative inspiratory reserve might be more affected in patients with COPD+CHF than in those with COPD only. Alternatively, reductions in EELV (induced by recruitment of abdominal expiratory muscles or increased elastic recoil, for example) and EILV (reduced EELV with or without reduced $\left.V_{T}\right)^{(15)}$ might preserve inspiratory fraction and relative inspiratory reserve despite a lower TLC in patients with COPD+CHF. Given that no previous studies have addressed these issues, there is still a substantial knowledge gap regarding the mechanical

Correspondence to:

Priscila A. Sperandio. Rua Francisco de Castro, 54, CEP 04020-050, São Paulo, SP, Brasil.

Tel.: 5511 5082-4420. E-mail: prissperandio@gmail.com

Financial support: Aline S. de Souza is the recipient of a grant from the Brazilian Conselho Nacional de Desenvolvimento Cientifico e Tecnológico (CNPq, National Council

for Scientific and Technological Development). 
interactions between COPD and CHF and their effects on the volumes available for inspiratory expansion in patients with COPD+CHF.

The objective of the present study was to compare inspiratory fraction and relative inspiratory reserve (and their determinants) between a carefully selected group of patients with COPD+CHF and a group of patients with COPD only. It was hypothesized that the characterization of the effect of $\mathrm{CHF}$ on these key physiological markers of COPD would advance the understanding of the mechanical and ventilatory constraints $^{(10)}$ faced by patients with COPD+CHF.

\section{METHODS}

\section{Sample}

In the present cross-sectional study with consecutive data collection, we included all consecutive patients who underwent whole-body plethysmography between February of 2012 and March of 2014 at the COPD+CHF outpatient clinic of the Universidade Federal de São Paulo (UNIFESP, Federal University of São Paulo) Department of Pulmonary Function and Exercise Physiology, located in the city of São Paulo, Brazil, and who presented with $\mathrm{FEV}_{1} / \mathrm{FVC}<0.7$ and left ventricular ejection fraction (LVEF) $\leq 45 \%$. All patients had previously been selected from among those treated at the Myocardial Infarction Outpatient Clinic of the aforementioned institution or at the Left Ventricular Dysfunction Outpatient Clinic of the Instituto Dante Pazzanese de Cardiologia (IDPC, Dante Pazzanese Institute of Cardiology), also in the city of São Paulo, Brazil. The patients in the COPD group $\left(\mathrm{FEV}_{1} / \mathrm{FVC}<0.7\right.$ and LVEF $\left.>45 \%\right)$ were selected from among those treated at the UNIFESP COPD Outpatient Clinic. Patients over 45 years of age with a smoking history of more than 10 pack-years were included. All patients were monitored by the same cardiologist and pulmonologist, undergoing standardized clinical assessment and receiving optimal treatment regimens for both diseases. Patients presenting with COPD exacerbation, decompensated $\mathrm{CHF}$, or both in the month prior to study entry were excluded, as were those with unstable angina. The study was approved by the Research Ethics Committees of UNIFESP (Protocol no. 19595) and IDPC (Protocol no. 68612).

\section{Measurements}

Spirometry (with forced and slow maneuvers) and whole-body plethysmography were performed with a Platinum Elite ${ }^{\mathrm{TM}}$ body plethysmograph (Medical Graphics Corp., St. Paul, MN, USA), in accordance with current recommendations. ${ }^{(18,19)}$ The following variables were assessed: FEV $_{1}$; FVC; slow vital capacity (SVC); TLC; $\mathrm{RV}$; thoracic gas volume, which was considered to be equivalent to functional residual capacity (FRC) in the present study; $V_{\mathrm{T}}$ (the mean of three breaths taken before the inhalation preceding the SVC maneuver); and IC. All variables were expressed in liters. On the basis of the aforementioned variables, EILV (EILV = $\left.\mathrm{FRC}+\mathrm{V}_{\mathrm{T}}\right)$, IRV $(\mathrm{IRV}=\mathrm{TLC}-\mathrm{EILV})$, and expiratory reserve volume $(\mathrm{ERV}=\mathrm{FRC}-\mathrm{RV})$ were calculated. ${ }^{(19)}$ The reference values were those obtained in a sample of Brazilian adults. ${ }^{(20,21)}$ The values that were analyzed in the present study were those obtained 20 min after the administration of $400 \mu \mathrm{g}$ of inhaled albuterol.

\section{Data analysis}

Statistical analysis was performed with the IBM SPSS Statistics software package, version 21.0 (IBM Corporation, Armonk, NY, USA). The Kolmogorov-Smirnov test was used in order to verify the normality of the data. Data were presented as mean and standard deviation. The independent sample t-test was used in order to compare the results between the groups. For qualitative variables, the chi-square test was used in order to assess differences between the groups. The level of statistical significance was set at $p<0.05$ for all tests.

\section{RESULTS}

A total of 86 patients ( 41 patients in the COPD $+\mathrm{CHF}$ group and 45 patients in the COPD group) were initially considered eligible for the present study. After exclusion of patients who were clinically unstable, those who were unable to perform advanced pulmonary function tests, and those whose tests were technically inadequate, 24 patients with COPD $+\mathrm{CHF}$ (23 of whom were male) and 32 patients with COPD only (28 of whom were male) were included.

The COPD+CHF and COPD groups were similar in terms of age ( $66 \pm 9$ vs. $64 \pm 6$ years), body mass index (26.5 \pm 3.7 vs. $\left.24.9 \pm 4.1 \mathrm{~kg} / \mathrm{m}^{2}\right)$, and smoking history (51.7 \pm 26.4 vs. $54.3 \pm 38.2$ pack-years). As expected, LVEF was significantly lower in the COPD + CHF group than in the COPD group (33 $\pm 7 \%$ vs. $68 \pm 4 \% ; p<0.01)$. The most common cause of CHF was ischemic cardiomyopathy $(n=13)$, followed by idiopathic etiology $(n=6)$. Most of the patients in the COPD+CHF group were under treatment with angiotensin-converting enzyme inhibitors/angiotensin receptor blockers $(n=21)$, diuretics $(n=20)$, or beta blockers $(n=18)$. There were no significant differences between the two groups regarding the frequency of use of long-acting bronchodilators, inhaled corticosteroids, or both $(p>0.05)$.

Although $\mathrm{FEV}_{1}$ was higher in the COPD+CHF group than in the COPD group, FVC and SVC were similar between the two groups (Table 1). Therefore, $\mathrm{FEV}_{1} / \mathrm{FVC}$ and $\mathrm{FEV}_{1} / \mathrm{SVC}$ were higher in the COPD+CHF group ( $\mathrm{p}$ $<0.05)$. In contrast, all major "static" lung volumes (RV, FRC, and TLC) were lower in the COPD+CHF group than in the COPD group. In the COPD group, there was a greater reduction in FRC than in RV, ERV therefore being lower in the COPD+CHF group. There were relatively proportional reductions in FRC and TLC in the two groups; therefore, IC was also comparable ( $p>0.05$; Table 1 and Figure 1A). A similar IC and a lower TLC resulted in a higher inspiratory fraction $(\mathrm{IC} / \mathrm{TLC})$ in the COPD+CHF group ( $p<0.05$; Table 
Table 1. Functional characteristics of the patients with COPD only and of those with COPD and chronic heart failure. ${ }^{a}$

\begin{tabular}{|c|c|c|}
\hline \multirow[t]{2}{*}{ Variable } & \multicolumn{2}{|c|}{ Group } \\
\hline & $\begin{array}{c}\text { COPD } \\
(n=32)\end{array}$ & $\begin{array}{c}\text { COPD + CHF } \\
(n=24)\end{array}$ \\
\hline \multicolumn{3}{|c|}{ Spirometry (with forced and slow maneuvers) } \\
\hline $\mathrm{FEV}_{1}, \mathrm{~L}$ & $1.33 \pm 0.55$ & $1.78 \pm 0.53^{*}$ \\
\hline $\mathrm{FEV}_{1}, \%$ predicted & $48.5 \pm 18.2$ & $58.4 \pm 16.0^{*}$ \\
\hline FVC, L & $2.81 \pm 0.67$ & $2.90 \pm 0.57$ \\
\hline $\mathrm{FEV}_{1} / \mathrm{FVC}$ & $0.46 \pm 0.12$ & $0.60 \pm 0.10^{*}$ \\
\hline SVC, L & $3.05 \pm 0.70$ & $3.12 \pm 0.53$ \\
\hline $\mathrm{FEV}_{1} / \mathrm{SVC}$ & $0.43 \pm 0.14$ & $0.57 \pm 0.10^{*}$ \\
\hline$V_{T}, L$ & $0.81 \pm 0.20$ & $1.04 \pm 0.34^{*}$ \\
\hline IC, L & $2.27 \pm 0.52$ & $2.34 \pm 0.55$ \\
\hline $\mathrm{FEF}_{25-75 \%}, \mathrm{~L} / \mathrm{s}$ & $0.61 \pm 0.44$ & $1.00 \pm 0.51^{*}$ \\
\hline \multicolumn{3}{|l|}{ Whole-body plethysmography } \\
\hline TLC, L & $6.71 \pm 1.10$ & $5.91 \pm 0.84^{*}$ \\
\hline TLC, \% predicted & $108.9 \pm 16.6$ & $89.3 \pm 15.5^{*}$ \\
\hline FRC, L & $4.42 \pm 1.10$ & $3.45 \pm 0.79^{*}$ \\
\hline FRC, \% predicted & $132.4 \pm 28.5$ & $104.4 \pm 35.2^{*}$ \\
\hline $\mathrm{RV}, \mathrm{L}$ & $3.36 \pm 0.80$ & $2.78 \pm 0.79^{*}$ \\
\hline RV, \% predicted & $165.4 \pm 44.8$ & $131.6 \pm 42.6^{*}$ \\
\hline EILV, L & $5.13 \pm 1.25$ & $4.52 \pm 0.99$ \\
\hline IRV, L & $1.60 \pm 0.61$ & $1.43 \pm 0.51$ \\
\hline ERV, L & $0.99 \pm 0.58$ & $0.68 \pm 0.43^{*}$ \\
\hline sRaw, $\mathrm{cmH}_{2} \mathrm{O} / \mathrm{s}$ & $19.17 \pm 14.80$ & $11.02 \pm 10.52^{*}$ \\
\hline \multicolumn{3}{|l|}{ Ratios } \\
\hline EILV/TLC & $0.75 \pm 0.10$ & $0.75 \pm 0.09$ \\
\hline $\mathrm{V}_{\mathrm{T}} / \mathrm{IC}$ & $0.35 \pm 0.12$ & $0.44 \pm 0.14^{*}$ \\
\hline IC/TLC & $0.36 \pm 0.10$ & $0.43 \pm 0.10^{*}$ \\
\hline $\mathrm{RV} / \mathrm{TLC}$ & $0.50 \pm 0.08$ & $0.46 \pm 0.08$ \\
\hline $\mathrm{FEF}_{25-75 \%} / \mathrm{FVC}$ & $0.22 \pm 0.11$ & $0.34 \pm 0.14^{*}$ \\
\hline $\mathrm{FEF}_{25-75 \%} / \mathrm{TLC}$ & $0.11 \pm 0.07$ & $0.18 \pm 0.07^{*}$ \\
\hline
\end{tabular}

CHF: chronic heart failure; SVC: slow vital capacity; $\mathrm{V}_{\mathrm{T}}$ : tidal volume; IC: inspiratory capacity; TLC: total lung capacity; FRC: functional residual capacity; RV: residual volume; EILV: end-inspiratory lung volume; IRV: inspiratory reserve volume; ERV: expiratory reserve volume; sRaw: specific airway resistance. ${ }^{\text {VValues expressed }}$ as mean $\pm \mathrm{SD}$. $* \mathrm{p}<0.05$ (independent sample t-test).

1 and Figure $1 \mathrm{~B})$. It is of note that the patients in the COPD+CHF group used only part of the higher inspiratory fraction available. Therefore, despite a higher $\mathrm{V}_{\mathrm{T}} / \mathrm{IC}$ ratio in the COPD+CHF group, IRV and relative inspiratory reserve-[1 - (EILV/TLC)]-were similar between the two groups ( $p<0.05$; Table 1 and Figure 1B).

\section{DISCUSSION}

To our knowledge, this is the first cross-sectional study with prospective data collection to compare inspiratory fraction and relative inspiratory reserve-(IC/TLC) and $\left[1\right.$ - (EILV/TLC)], respectively ${ }^{(3-5)}$-as well as their determinants, between patients with COPD+CHF and those with COPD only. The main findings of the present study were that a) in comparison with the patients with COPD only, those with COPD +CHF showed a relatively greater reduction in FRC than in TLC and RV; b) consequently, there was no difference between the two groups regarding IC, but there was an increase in inspiratory fraction (IC/TLC); c) the patients with
COPD + CHF used only part of the higher inspiratory fraction available, given that relative inspiratory reserve-[1 - (EILV/TLC)]-was similar between the two groups. Therefore, our results indicate that, despite the restrictive effects of $\mathrm{CHF}$, there was not only a relative increase in inspiratory limits (a higher inspiratory fraction $)^{(3,4)}$ but also an admirably judicious use of those limits, given that a "critical" IRV was preserved, $(2,22)$ i.e., a similar relative inspiratory reserve.

Over the last two decades, there have been considerable advances in the understanding of the crucial role that a precise regulation of operating lung volumes plays in reducing the metabolic demands associated with ventilation and the sensation of dyspnea in patients with COPD. (2) The present study adds to this line of reasoning by showing that, even in the presence of comorbidities associated with reduced static lung volumes (i.e., CHF), ${ }^{(13-16)}$ the precise regulation of a "safe end-inspiratory reserve volume" for mechanical operation of the system at maximum capacity (i.e., TLC) appears to remain intact. ${ }^{23,24)}$ Although our patients 

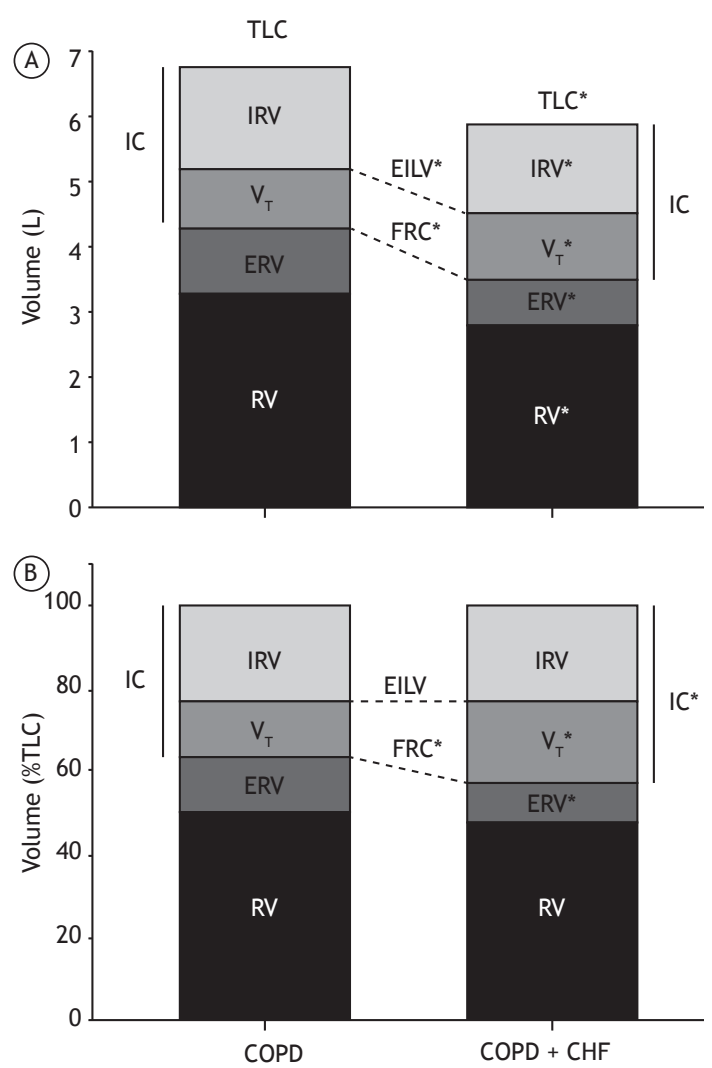

Figure 1. Lung volumes and capacities expressed as absolute values (in A) and corrected for differences in total lung capacity (in B) in patients with COPD only and in those with COPD and chronic heart failure (CHF). TLC: total lung capacity; RV: residual volume; ERV: expiratory reserve volume; $\mathrm{V}_{\mathrm{T}}$ : tidal volume; IRV: inspiratory reserve volume; FRC: functional residual capacity; EILV: endinspiratory lung volume; and IC: inspiratory capacity. ${ }^{*} \mathrm{p}$ $<0.05$ (independent sample t-test).

were not evaluated during exercise, the aforementioned strategy suggests that both groups had the same IRV available for consumption at higher ventilatory demands. ${ }^{(2,23,24)}$ However, because we did not directly measure the work of breathing in the present study, we cannot guarantee that the lower operating lung volumes observed in the COPD+CHF group would be enough to overcome the likely increase in elastic recoil associated with $\mathrm{CHF}^{(10)}$

The physiological mechanisms underlying the precise adjustment of IRV in patients with COPD remain largely unknown. However, the relative (i.e., fractional) nature of this adjustment is noteworthy; $V_{T}$ increases only enough to maintain a "critical" IRV ${ }_{\boldsymbol{r}}^{(2,23,24)}$ even if there is still room for further increases. In fact, Faisal et al. have recently demonstrated that this adjustment remains precise in physiologically and structurally opposite diseases (COPD and interstitial lung disease). (25) The way in which the respiratory system precisely defines this threshold appears to involve an awareness (either acquired by experience or innate) of the maximum capacity available. The price of excessive elastic recoil is clearly avoided. ${ }^{(24)}$ Although we do not know the extent to which the combination of COPD and CHF effectively increases dead space volume, this is a plausible hypothesis, given that lung perfusion might be reduced in areas in which ventilation is relatively preserved. (26) Therefore, it makes sense that, in such patients, $V_{T}$ is somewhat higher in order to reduce the dead space to tidal volume ratio $\left(\mathrm{V}_{\mathrm{D}} / \mathrm{V}_{\mathrm{T}}\right)$. It is therefore possible that the limits to increases in $\mathrm{V}_{\mathrm{T}}$ (with concomitant reduction in $\mathrm{V}_{\mathrm{D}} / \mathrm{V}_{\mathrm{T}}$ ) are also determined by humoral factors, i.e., the $\mathrm{V}_{\mathrm{T}}$ required in order to reduce $\mathrm{V}_{\mathrm{D}} / \mathrm{V}_{\mathrm{T}}$, thus allowing minute $\mathrm{PaCO}_{2}$ variations that are close to its set point. ${ }^{(27)}$ In fact, given that $\mathrm{PaCO}_{2}$ can be set at slightly lower values in patients with COPD $+\mathrm{CHF}$, the dynamic regulation of $\mathrm{V}_{\mathrm{D}} / \mathrm{V}_{\mathrm{T}}$ appears to be of particular relevance for such patients.

The fact that there was a reduction in FRC is of crucial importance for the understanding of our findings. Given that the reduction in FRC overcame the decrements in $R V$, there was a significant decrease in ERV. This confirmed the premise that, in order to maintain $\mathrm{V}_{\mathrm{T}}$ and IRV, patients with COPD choose to pay the price of nearly reaching maximal expiratory volumes, despite the fact that this can affect the efficiency of pulmonary gas exchange and reduce flow reserves. However, it is of note that $\mathrm{CHF}$ probably increases lung elastic recoil and mean expiratory flow (the latter particularly during exercise). ${ }^{(10)}$ Therefore, at least in stable patients, reduced flow reserves might not necessarily be associated with increased expiratory flow limitation in COPD +CHF. The underlying reasons for a relatively greater reduction in FRC remain unclear and include the following: a) increased tonic activity of abdominal expiratory muscles $(28,29)$; b) reduced small airway obstruction, the small airways being particularly relevant for determining volume balance in COPD patients ${ }^{(28)}$; and c) increased rate of lung emptying in units with higher time constants, i.e., those particularly affecting "lower" lung volumes (near RV), as a result of a higher expiratory flow rate and cardiomegaly. ${ }^{(30)}$ Given that there was no difference in body mass index between the two groups (and given that none of the patients had ascites), the hypothesis that TLC was lower in the COPD+CHF group because overweight and obesity were more common in that group does not seem plausible. ${ }^{(31)}$ In addition, lung volumes were nearly normal in the COPD+CHF group, whereas, in the COPD group, they were increased, as expected. Therefore, if we assume that the incidence of $\mathrm{CHF}$ is higher than its prevalence, ${ }^{(32)} \mathrm{CHF}$ is likely to lead to a "pseudonormalization" of static lung volumes in COPD. However, longitudinal studies are needed in order to test this hypothesis.

What is the clinical applicability of our results? The remarkable maintenance of IRV in the COPD+CHF group demonstrates that it is particularly critical to maintain an adequate IC from a lower EELV in such patients. Therefore, although the patients with COPD+CHF were less hyperinflated (had a lower TLC) than those with COPD only, a reduction in air trapping appears to be fundamental to a downward shift in operating lung 
volumes. In other words, only optimal bronchodilator therapy can effectively increase IC and reduce the EELV/TLC ratio in patients with COPD+CHF. In addition, supplemental mechanisms reducing TLC (pleural effusion, congestion, inspiratory muscle weakness, and morbid obesity) ${ }^{(10-12)}$ should be minimized in order to restore maximum inspiratory thresholds.

The present study has some important limitations that should be noted. Our sample of patients was relatively small in comparison with those of large retrospective epidemiological studies. However, before undergoing pulmonary function testing, all of the participants in the present study were carefully optimized from a clinical standpoint by the coordinated efforts of and consensus between a cardiologist and a pulmonologist. Several confounders were thus avoided, including airway obstruction and air trapping secondary to pulmonary edema and small airway compression in unstable patients with CHF. In addition, the results presented here refer to post-bronchodilator plethysmography. Therefore, our results probably provide a picture of the best possible lung function in those patients. Another possible criticism is that $\mathrm{FEV}_{1}$ and $\mathrm{FEV}_{1} / \mathrm{FVC}$ were higher in the patients in the COPD+CHF group than in those in the COPD group, meaning that the former were less "obstructed" than the latter. Indeed, we cannot rule out the possibility of a selection bias toward less severely ill patients who were able to perform whole-body plethysmography adequately. However, it is extremely difficult to match such patients by $\mathrm{FEV}_{1}$. Guder et al. argued that $\mathrm{CHF}$ tends to overestimate the severity of
COPD (as determined by $\mathrm{FEV}_{1}$ ) because of reduced lung volumes. ${ }^{(17)}$ However, the increased airflow resulting from the increased elastic recoil induced by $\mathrm{CHF}^{(33-35)}$ tends to increase $\mathrm{FEV}_{1}$. Another complicating factor is that the functional effects of CHF can be influenced by the relative predominance of emphysema or airway disease (chronic bronchitis). In the present study, the fact that there was no difference between the two groups in terms of the RV/TLC ratio suggests that they were somewhat comparable despite the differences in $\mathrm{FEV}_{1}$. Further studies are needed in order to define the best approach to the functional pairing of patients with COPD+CHF and those with COPD only.

In conclusion, despite the significant restrictive effects of CHF (reduced TLC), reductions in FRC and ERV preserve IC and increase inspiratory fraction (IC/TLC) in patients with COPD+CHF. However, in order to preserve a "critical" IRV, such patients use only part of this higher inspiratory fraction, possibly in order to reduce elastic recoil and, consequently, the sensation of dyspnea. The present study lays the foundation for future studies comparing our findings regarding resting lung volumes with mechanical, ventilatory, and sensory responses during exercise in patients with COPD+CHF.

\section{ACKNOWLEDGMENTS}

We would like to thank the IDPC, as well as the UNIFESP Departments of Pulmonology and Cardiology, for making the present study possible.

\section{REFERENCES}

1. O'Donnell DE. Ventilatory limitations in chronic obstructive pulmonary disease. Med Sci Sports Exerc. 2001;33(7 Suppl):S647-55. http:// dx.doi.org/10.1097/00005768-200107001-00002

2. O'Donnell DE, Laveneziana P, Webb K, Neder JA. Chronic obstructive pulmonary disease: clinical integrative physiology. Clin Chest Med. 2014;35(1):51-69. http://dx.doi.org/10.1016/j.ccm.2013.09.008

3. Casanova C, Cote C, de Torres JP, Aguirre-Jaime A, Marin JM, Pinto-Plata $V$, et al. Inspiratory-to-total lung capacity ratio predicts mortality in patients with chronic obstructive pulmonary disease. Am J Respir Crit Care Med. 2005;171(6):591-7. http://dx.doi.org/10.1164/ rccm.200407-8670C

4. Albuquerque AL, Nery LE, Villaça DS, Machado TY, Oliveira CC, Paes AT, et al. Inspiratory fraction and exercise impairment in COPD patients GOLD stages II-III. Eur Respir J. 2006;28(5):939-44. http:// dx.doi.org/10.1183/09031936.06.00040506

5. O'Donnell DE, Lam M, Webb KA. Measurement of symptoms, lung hyperinflation, and endurance during exercise in chronic obstructive pulmonary disease. Am J Respir Crit Care Med. 1998;158(5 Pt 1):1557-65. http://dx.doi.org/10.1164/ajrccm.158.5.9804004

6. O'Donnell DE. Hyperinflation, dyspnea, and exercise intolerance in chronic obstructive pulmonary disease. Proc Am Thorac Soc. 2006;3(2):180-4. http://dx.doi.org/10.1513/pats.200508-093DO

7. Rutten FH, Cramer MJ, Lammers JW, Grobbee DE, Hoes AW. Heart failure and chronic obstructive pulmonary disease: An ignored combination? Eur J Heart Fail. 2006;8(7):706-11. http://dx.doi. org/10.1016/j.ejheart.2006.01.010

8. Güder G, Rutten FH. Comorbidity of heart failure and chronic obstructive pulmonary disease: more than coincidence. Curr Heart Fail Rep. 2014;11(3):337-46. http://dx.doi.org/10.1007/s11897-0140212-x

9. Güder G, Brenner S, Störk S, Hoes A, Rutten FH. Chronic obstructive pulmonary disease in heart failure: accurate diagnosis and treatment. Eur J Heart Fail. 2014;16(12):1273-82. http://dx.doi.org/10.1002/ ejhf.183

10. Cross TJ, Sabapathy S, Beck KC, Morris NR, Johnson BD. The resistive and elastic work of breathing during exercise in patients with chronic heart failure. Eur Respir J. 2012;39(6):1449-57. http:// dx.doi.org/10.1183/09031936.00125011

11. Apostolo A, Giusti G, Gargiulo P, Bussotti M, Agostoni P. Lungs in heart failure. Pulm Med. 2012;2012:952741. http://dx.doi. org/10.1155/2012/952741

12. Apostolo A, Laveneziana P, Palange P, Agalbato C, Molle R, Popovic $D$, et al. Impact of chronic obstructive pulmonary disease on exercise ventilatory efficiency in heart failure. Int J Cardiol. 2015;189:134-40. http://dx.doi.org/10.1016/j.ijcard.2015.03.422

13. Faggiano $P$. Abnormalities of pulmonary function in congestive heart failure. Int J Cardiol. 1994;44(1):1-8. http://dx.doi.org/10.1016/01675273(94)90060-4

14. Dimopoulou I, Daganou M, Tsintzas OK, Tzelepis GE. Effects of severity of long-standing congestive heart failure on pulmonary function. Respir Med. 1998;92(12):1321-5. http://dx.doi.org/10.1016/ S0954-6111(98)90136-6

15. Lalande $S$, Johnson BD. Breathing strategy to preserve exercising cardiac function in patients with heart failure. Med Hypotheses. 2010;74(3):416-21. http://dx.doi.org/10.1016/j.mehy.2009.09.030

16. Olson TP, Denzer DL, Sinnett WL, Wilson T, Johnson BD. Prognostic value of resting pulmonary function in heart failure. Clin Med Insights Circ Respir Pulm Med. 2013;7:35-43. http://dx.doi.org/10.4137/ ccrpm.s12525

17. Güder $G$, Rutten FH, Brenner $S$, Angermann $C E$, Berliner D, Ert $G$, et al. The impact of heart failure on the classification of COPD severity. J Card Fail. 2012;18(8):637-44. http://dx.doi.org/10.1016/j. cardfail.2012.05.008

18. Miller MR, Hankinson J, Brusasco V, Burgos F, Casaburi R, Coates A, et al. Standardisation of spirometry. Eur Respir J. 2005;26(2):319-38. 
http://dx.doi.org/10.1183/09031936.05.00034805

19. Wanger J, Clausen JL, Coates A, Pedersen OF, Brusasco V, Burgos $F$, et al. Standardisation of the measurement of lung volumes. Eur Respir J. 2005;26(3):511-22. http://dx.doi.org/10.1183/09031936.05 .00035005

20. Neder JA, Andreoni S, Castelo-Filho A, Nery LE. Reference values for lung function tests. I. Static volumes. Braz J Med Biol Res. 1999;32(6):703-17. http://dx.doi.org/10.1590/s0100$879 \times 1999000600006$

21. Pereira CA, Sato T, Rodrigues SC. New reference values for forced spirometry in white adults in Brazil. J Bras Pneumol. 2007;33(4):397406. http://dx.doi.org/10.1590/S1806-37132007000400008

22. O'Donnell DE, Webb KA. The major limitation to exercise performance in COPD is dynamic hyperinflation. J Appl Physio (1985). 2008;105(2):753-5; discussion 755-7

23. O'Donnell DE, Guenette JA, Maltais F, Webb KA. Decline of resting inspiratory capacity in COPD: the impact on breathing pattern, dyspnea, and ventilatory capacity during exercise. Chest. 2012;141(3):753-62. http://dx.doi.org/10.1378/chest.11-0787

24. Casaburi R, Rennard SI. Exercise limitation in chronic obstructive pulmonary disease. The O'Donnell threshold. Am J Respir Crit Care Med. 2015 Apr 15;191(8):873-5. http://dx.doi.org/10.1164/ rccm.201501-0084ED

25. Faisal A, Alghamdi BJ, Ciavaglia CE, Elbehairy AF, Webb KA, Ora $J$, et al. Common Mechanisms of Dyspnea in Chronic Interstitial and Obstructive Lung Disorders. Am J Respir Crit Care Med. 2016;193(3):299-309. http://dx.doi.org/10.1164/rccm.201504$08410 \mathrm{C}$

26. Neder JA, Arbex FF, Alencar MC, O'Donnell CD, Cory J, Webb KA, et al. Exercise ventilatory inefficiency in mild to end stage COPD. Eur Respir J. 2015;45(2):377-87. http://dx.doi org/10.1183/09031936.00135514

27. Whipp BJ, Ward SA, Wasserman K. Ventilatory responses to exercise and their control in man. Am Rev Respir Dis. 1984;129(2 Pt 2):S17-20. http://dx.doi.org/10.1164/arrd.1984.129.2P2.S17

28. Macklem PT. Respiratory mechanics. Annu Rev Physiol. 1978;40:157 84. http://dx.doi.org/10.1146/annurev.ph.40.030178.001105

29. Aliverti A, Cala SJ, Duranti R, Ferrigno G, Kenyon CM, Pedotti A, et al Human respiratory muscle actions and control during exercise. J App Physiol (1985). 1997;83(4):1256-69.

30. Olson TP, Beck KC, Johnson BD. Pulmonary function changes associated with cardiomegaly in chronic heart failure. J Card Fail. 2007;13(2):100-7. http://dx.doi.org/10.1016/j.cardfail.2006.10.018

31. O'Donnell DE, Deesomchok A, Lam YM, Guenette JA Amornputtisathaporn N, Forkert L, et al. Effects of BMI on static lung volumes in patients with airway obstruction. Chest. 2011;140(2):4618. http://dx.doi.org/10.1378/chest.10-2582

32. Hawkins NM, Petrie MC, Jhund PS, Chalmers GW, Dunn FG McMurray JJ. Heart failure and chronic obstructive pulmonary disease: diagnostic pitfalls and epidemiology. Eur $\mathrm{J}$ Heart Fail. 2009;11(2):130-9. http://dx.doi.org/10.1093/eurjhf/hfn013

33. Gazetopoulos N, Davies H, Oliver C, Deuchar D. Ventilation and haemodynamics in heart disease. Br Heart J. 1966;28(1):1-15. http:// dx.doi.org/10.1136/hrt.28.1.1

34. Ingram R Jr, McFadden ER Jr. Respiratory changes during exercise in patients with pulmonary venous hypertension. Prog Cardiovasc Dis. 1976;19(2):109-15. http://dx.doi.org/10.1016/0033-0620(76)90019-0

35. Johnson BD, Beck KC, Olson LJ, O'Malley KA, Allison TG, Squires RW, et al. Ventilatory constraints during exercise in patients with chronic heart failure. Chest. 2000;117(2):321-32. http://dx.doi. org/10.1378/chest.117.2.321 